\title{
ARRB1 suppresses the activation of hepatic macrophages via modulating endoplasmic reticulum stress in lipopolysaccharide-induced acute liver injury
}

\author{
Yiming Lei ${ }^{1,2,3}$, Sizhe Wan ${ }^{1,2,3}$, Huiling Liu ${ }^{1,2}$, Haoxiong Zhou ${ }^{1,2}$, Lingjun Chen ${ }^{1,2}$, Yidong Yang ${ }^{1,2 凶}$ and Bin Wu ${ }^{1,2} \bowtie$
}

(c) The Author(s) 2021

Acute liver injury (ALI) caused by multiple inflammatory responses is a monocyte-/macrophage-mediated liver injury that is associated with high morbidity and mortality. Liver macrophage activation is a vital event that triggers ALI. However, the mechanism of liver macrophage activation has not been fully elucidated. This study examined the role of $\beta$-arrestin1 (ARRB1) in wild-type (WT) and ARRB1-knockout (ARRB1-KO) mouse models of ALI induced by lipopolysaccharide (LPS), and ARRB1-KO mice exhibited more severe inflammatory injury and liver macrophage activation compared to WT mice. We found that LPS treatment reduced the expression level of ARRB1 in Raw264.7 and THP-1 cell lines, and mouse primary hepatic macrophages. Overexpression of ARRB1 in Raw264.7 and THP-1 cell lines significantly attenuated LPS-induced liver macrophage activation, such as transformation in cell morphology and enhanced expression of proinflammatory cytokines (tumor necrosis factor- $\alpha$, interleukin- $1 \beta$, and interleukin6), while downregulation of $A R R B 1$ by small interfering RNA and ARRB1 deficiency in primary hepatic macrophages both aggravated macrophage activation. Moreover, overexpression of ARRB1 suppressed LPS-induced endoplasmic reticulum (ER) stress in liver macrophages, and inhibition of ER stress impeded excessive hepatic macrophage activation induced by downregulation of ARRB1. Our data demonstrate that ARRB1 relieves LPS-induced ALI through the ER stress pathway to regulate hepatic macrophage activation and that ARRB1 may be a potential therapeutic target for ALI.

Cell Death Discovery (2021)7:223; https://doi.org/10.1038/s41420-021-00615-9

\section{INTRODUCTION}

Acute liver injury (ALI) is a complex and life-threatening disease caused by multiple inflammation-related etiologies, such as sepsis, alcohol addiction, metabolic syndrome, drug-induced liver disease, and virus or bacterial infection [1, 2], and is associated with high mortality due to a lack of specific therapy. Despite considerable differences in these etiologies, the pathophysiological manifestations of ALI are mainly hepatocyte injury, inflammatory cell infiltration and activation, and disordered inflammatory response [3]. In this pathologic process, liver macrophages (Kupffer cells) play a crucial role as modulators of the immune system [4], and activated macrophages regulate the immune response by recognizing and expressing antigens and releasing inflammatory cytokines [5]. Activated liver macrophages display increased size, morphology of polygons, pseudopodia, and enhanced expression of inflammatory cytokines, leading to amplification of the inflammatory response cascade and sustaining hepatocyte damage [6]. Hence, controlling overactivated liver macrophages is a potentially crucial strategy for preventing and curing ALI. Previous studies have confirmed that the performance of lipopolysaccharide (LPS), a well-known inflammatory ligand, can establish experimental mouse ALI models [7]. LPS from gramnegative bacteria can activate macrophages to release a variety of inflammatory cytokines including tumor necrosis factor-a (TNF-a), interleukin-1 $\beta$ (IL-1 $\beta$ ), and IL-6, which in turn lead to massive hepatocyte apoptosis or necrosis along with aspartate aminotransferase (AST) and alanine aminotransferase (ALT) release into peripheral blood [8].

$\beta$-Arrestin1 (ARRB1) belongs to the arrestin family originally identified as a multifunctional adaptor protein that negatively regulates the desensitization and internalization of G-proteincoupled receptors (GPCRs) [9]. Recent studies have also indicated that ARRB1, as a mediator rather than simply a terminator of GPCR signaling, can regulate G-protein-independent signaling cascades or act as a scaffold to connect various receptors to downstream signaling pathways, such as the c-Jun N-terminal kinase and nuclear factor-KB (NF-kB) cascades [10, 11]. In addition, ARRB1 is closely related to the inflammatory response. It was reported that in LPS/ATP-stimulated BV2 microglia, overexpression of ARRB1 attenuated the inhibitory effect of a specific nicotinic acetylcholine receptor agonist on inflammasome activation [12]. Deficiency of ARRB1 abolished prostaglandin E2elicited suppression of IL-10 production in LPS-elicited inflammatory conditions [13]. Sharma et al. revealed that ARRB1 in nonhematopoietic cells was critical and sufficient for inhibiting sepsis-induced inflammation [14]. Nevertheless, there are few

\footnotetext{
${ }^{1}$ Department of Gastroenterology, The Third Affiliated Hospital of Sun Yat-Sen University, Guangzhou, Guangdong Province, China. ${ }^{2}$ Guangdong Provincial Key Laboratory of Liver Disease Research, Guangzhou, Guangdong Province, China. ${ }^{3}$ These authors contributed equally: Yiming Lei, Sizhe Wan. ${ }^{凶}$ email: yangyd6@mail.sysu.edu.cn; wubin6@mail.sysu.edu.cn Edited by Inna Lavrik
}

Received: 7 May 2021 Revised: 7 July 2021 Accepted: 26 July 2021

Published online: 28 August 2021 
A

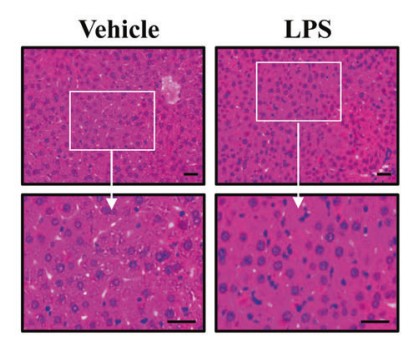

H\&E
B

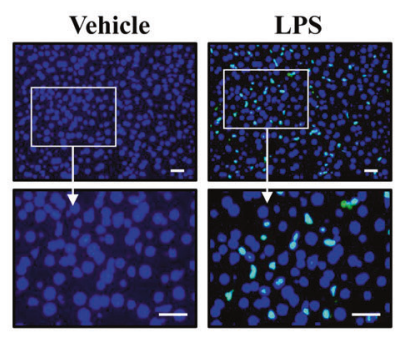

TUNEL
C

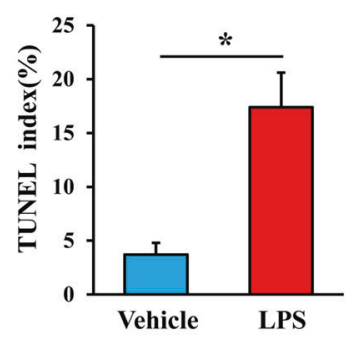

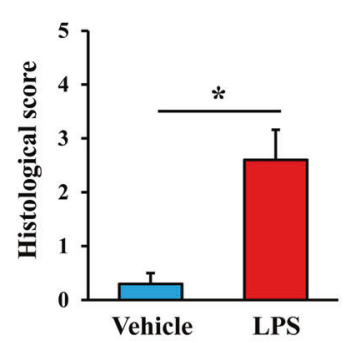

D

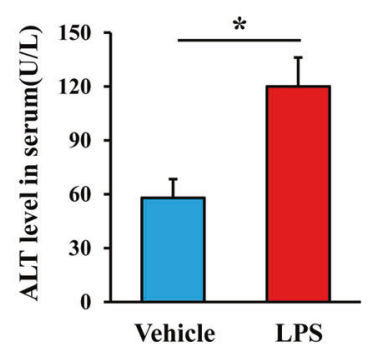

G

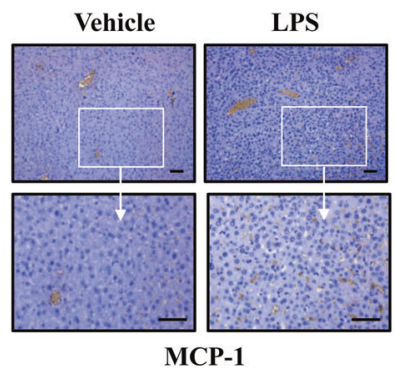

E

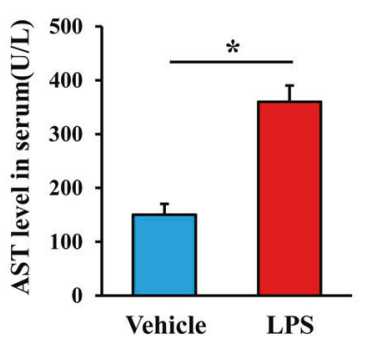

$\mathbf{F}$

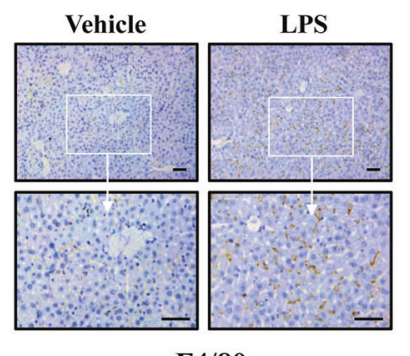

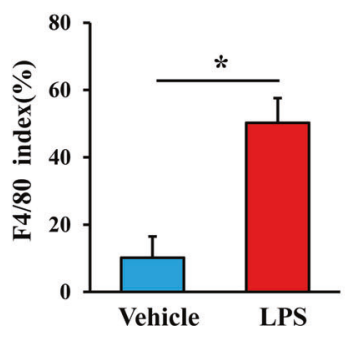

F4/80

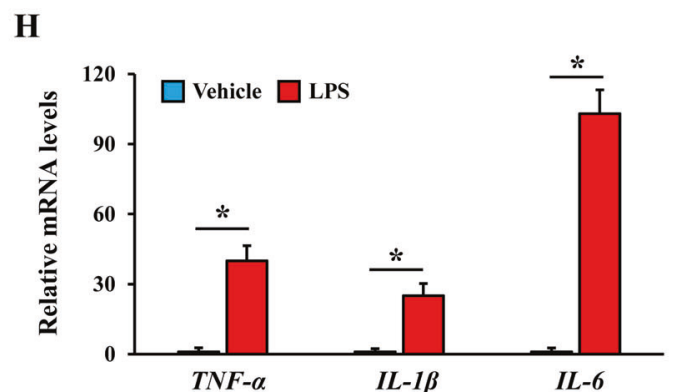

Fig. 1 LPS induced acute liver injury and hepatic macrophage infiltration. Mice were intraperitoneally administered either physiological saline (vehicle) or a single LPS injection $(5 \mathrm{mg} / \mathrm{kg}$ ), and the mouse livers were harvested at $6 \mathrm{~h}$. A Representative H\&E staining of livers in vehicle- and LPS-induced WT mice (scale bar: $25 \mu \mathrm{m}$ ). B TUNEL staining of livers in vehicle- and LPS-induced mice (scale bar: $25 \mu \mathrm{m}$ ), and the positive TUNEL index was scored. C Liver histology scoring in vehicle- and LPS-induced mice. D, E Serum ALT and AST levels in vehicle- and LPS-induced mice. F, G F4/80 and MCP-1 staining of livers in vehicle- and LPS-induced mice (scale bar: $50 \mu \mathrm{m}$ ), and the positive F4/80 and MCP-1 indexes were scored. H TNF- $a, I L-1 \beta$, and IL-6 mRNA levels in vehicle- and LPS-induced WT mouse liver tissues were analyzed by realtime PCR. All values are the mean \pm SD $\left(n=6\right.$ in each group). ${ }^{*} P<0.05$ by Student's $t$ test.

reports about the regulation of ARRB1 on macrophage activation in the inflammatory microenvironment. ARRB1 plays a crucial role in the occurrence and development of numerous diseases. In our previous study, we found that ARRB1 is involved in hepatocellular carcinogenesis through inflammation-mediated Akt signaling [15] and the pathological progression of portal hypertensive gastropathy [16]. However, our knowledge of the function of ARRB1 in ALI is limited.

Endoplasmic reticulum (ER) stress is a pathological status of subcellular organelles triggered by misfolded and unfolded protein aggregation and $\mathrm{Ca}^{2+}$ balance disorder in the ER lumen, and has long been considered to have a promoting role in ALI. Emerging evidence has indicated that ER stress signaling has close cross-talk with macrophage activation [17]. Wei et al. reported that secreted Golgi protein 73 from tumor cells stimulated activation of neighboring macrophages in the liver to release cytokines and chemokines via ER stress [18]. In addition, ARRB1 was reported to protect against ER stress/PUMAinduced mucosal epithelial apoptosis in portal hypertensive gastropathy [19].
In our present study, we demonstrated that ARRB1 deficiency aggravated LPS-induced ALI, and overexpression of ARRB1 suppressed liver macrophage activation and the release of inflammatory cytokines. Inhibition of ER stress attenuated more severe ALI and liver macrophage activation induced by downregulation of ARRB1. Overall, our findings suggest that ARRB1 protects against LPSinduced ALI via ER stress and that targeting ARRB1-mediated ER stress may provide a potential method for ALI therapy.

\section{RESULTS}

LPS induces ALI along with activation of hepatic macrophages LPS is the part of the outer membranes of gram-negative bacteria, which induces multiple inflammatory responses. In this study, wild-type (WT) mice were intraperitoneally administered either physiological saline or a single LPS injection $(5 \mathrm{mg} / \mathrm{kg})$ to induce ALI, and the mouse livers were harvested after $6 \mathrm{~h}$. Hematoxylin and eosin (H\&E) staining of liver tissues in LPSinduced mice showed distinct histological abnormalities, including liver congestion, hepatocyte swelling, liver rope destruction, 
and inflammatory cell infiltration (Fig. 1A). According to previous reports [20], the histological scores of the pathological films were obtained, and LPS-induced mice showed higher histological scores compared with mice injected with physiological saline (Fig. 1C). Terminal deoxynucleotidyl transferase dUTP nick-end labeling (TUNEL) staining of livers also showed more apoptotic signals in LPS-induced mice (Fig. 1B). Serum ALT and AST levels were markedly higher after mice were injected with LPS (Fig. 1D, E). F4/ 80 is a marker of hepatic macrophages and monocyte chemotactic protein-1 (MCP-1) is close to the activation of hepatic macrophages. Myeloperoxidase (MPO) reflects the amount of neutrophils. Immunohistochemical (IHC) staining showed more positive F4/80, MCP-1, and MPO signals in the livers of mice injected with LPS (Fig. 1F, G and Supplementary Fig. S1A), suggesting that more inflammatory cells infiltrated and were activated in the livers of LPS-induced mice, especially hepatic macrophages. Meanwhile, the levels of proinflammatory factors including $T N F-a, I L-1 \beta$, and $I L-6$ increased in the livers of LPSinduced mice (Fig. $1 \mathrm{H})$, further reflecting the activation of hepatic macrophages.

\section{ARRB1 is involved in LPS-induced activation of liver macrophages}

Our previous study demonstrated that ARRB1 played a significant role in hepatocyte proliferation and hepatic stellate cell activation $[15,21]$. Therefore, we sought to explore whether ARRB1 was involved in LPS-induced activation of liver macrophages in ALI. Two kinds of macrophage cell lines (Raw264.7 and THP-1) were treated with different concentrations of LPS $(0,0.5,1$, and $2 \mu \mathrm{g} / \mathrm{ml})$ for $6 \mathrm{~h}$. Interestingly, we found that Raw264.7 and THP-1 cells obviously exhibited characteristics of activated macrophages when stimulated with LPS $(1 \mu \mathrm{g} / \mathrm{ml})$, such as increased size, polygonization, and much more and longer pseudopodia (Fig. 2A). Meanwhile, the cells were treated with LPS $(1 \mu \mathrm{g} / \mathrm{ml})$ for different times $(0,6,12$, and $18 \mathrm{~h})$. The results showed that Raw264.7 and THP-1 cells began to exhibit characteristics of activated macrophages when stimulated with LPS for $6 \mathrm{~h}$ (Fig. 2B). Moreover, we collected the total proteins from Raw264.7 and THP-1 cells stimulated with LPS at different concentrations and times. The results indicated that the expression level of ARRB1 protein was reduced and the levels of proinflammatory cytokines (TNF- $a, I L-1 \beta$, and IL-6) increased along with the activation of macrophages (Fig. 2C, D). Consistently, we observed that the transcription of ARRB1 was reduced following LPS stimulation (Fig. 2E, F). Furthermore, primary hepatic macrophages (PHMs) of WT mice were extracted and treated with LPS $(1 \mu \mathrm{g} / \mathrm{ml}, 6 \mathrm{~h})$, and the expression level of ARRB1 messenger RNA (mRNA) was significantly downregulated following LPS stimulation (Fig. 2G). These results implied that ARRB1 may correlate with LPS- induced activation of liver macrophages.

\section{ARRB1 deficiency facilitates LPS-induced ALI and activation of liver macrophages}

Our previous study demonstrated that ARRB1 was involved in chronic liver diseases, such as liver cirrhosis and hepatocellular carcinoma $[15,21]$. To confirm the role of ARRB1 in LPS-induced ALI, we generated an LPS ( $5 \mathrm{mg} / \mathrm{kg}$ )-induced ALI model in ARRB1deficient mice (ARRB1-KO) and WT mice (Supplementary Fig. S2A, $B)$. H\&E-stained liver sections revealed that there were no significant differences in liver tissue structure between WT and ARRB1-KO mice without LPS treatment, while following LPS treatment, the livers of ARRB1-KO mice exhibited more severe liver congestion, hepatocyte swelling, liver rope destruction, and inflammatory cell infiltration than the livers of WT mice (Fig. 3A). Consistently, LPS-induced ARRB1-KO mice showed a higher histological score compared with WT mice injected with LPS (Fig. 3C). TUNEL staining of livers also showed more apoptotic signals in LPS-induced ARRB1-KO mice than in LPS-induced WT mice (Fig. 3B). Meanwhile, serum ALT and AST levels were also obviously higher in LPS-induced ARRB1-KO mice compared to LPSinduced WT mice (Fig. 3D, E). In addition, we found an increase in F4/80 and MCP-1 signals in the livers of LPS-induced ARRB1-KO mice compared to LPS-induced WT mice (Fig. 3F). Furthermore, we tested the expression levels of TNF- $a, I L-1 \beta$, and $I L-6$ in the liver by real-time $P C R$, and the results showed higher levels of proinflammatory cytokines in ARRB1-KO mice with LPS treatment compared to LPS-induced WT mice (Fig. 3G). Together, these results confirmed that $A R R B 1$ deficiency promoted LPS-induced $\mathrm{ALI}$ and activation of liver macrophages.

\section{Overexpression of $A R R B 1$ inhibits activation of hepatic macrophages induced by LPS}

In order to further explore the role of ARRB1 in macrophage activation, we established Raw264.7 and THP-1 cell lines in which ARRB1 was stably overexpressed by lentivirus (Supplementary Fig. $\mathrm{S} 2 \mathrm{C}$ ) and examined whether ARRB1-overexpressing cells display resistance to macrophage activation. We treated control vector- or ARRB1-overexpressing cells with LPS $(1 \mu \mathrm{g} / \mathrm{ml})$ for $6 \mathrm{~h}$ and found that vector cells with LPS treatment exhibited evident characteristics of activated macrophages, including increased size, polygonization, and more and longer pseudopodium, but it was reversed in ARRB1-overexpressing Raw264.7 and THP-1 cells (Fig. $4 \mathrm{~A})$. Then, we stimulated PHMs isolated from WT and ARRB1-KO mice with half the concentration of LPS $(0.5 \mu \mathrm{g} / \mathrm{ml})$. Conversely, ARRB1-KO mouse PHMs displayed characteristics of activated macrophages accompanied by polygonization and the appearance of pseudopodia, while it cannot be observed in WT mouse PHMs with half the concentration of LPS (Fig. 4B). To further detect cell activation, we tested the levels of $T N F-a, I L-1 \beta$, and $I L-6$ by realtime PCR in vector- or ARRB1-overexpressing Raw264.7 and THP-1 cells treated with LPS $(1 \mu \mathrm{g} / \mathrm{ml})$ treatment for $6 \mathrm{~h}$ and mouse PHMs with LPS $(0.5 \mu \mathrm{g} / \mathrm{ml})$ treatment. The results showed that ARRB1 overexpression inhibited the enhanced expression levels of TNF- $a$, $I L-1 \beta$, and IL- 6 induced by LPS stimulation, but ARRB1 knockout contributed to the increased levels of these proinflammatory cytokines in mouse PHMs (Fig. 4C-K). These results indicated that overexpression of $A R R B 1$ suppressed the activation of hepatic macrophages induced by LPS.

\section{ARRB1 restrains LPS-induced ER stress in hepatic macrophages}

ER stress signaling has been reported to be a vital promotor of LPS-induced ALI [22]. We next determined whether ER stress was related to ARRB1 in LPS-induced ALI. Indeed, the evidence obtained by double immunofluorescent staining for F4/80 and GRP78, a core protein in ER stress, revealed that most of the elevated positive signals overlapped in the liver sections of LPSinduced ARRB1-KO mice instead of LPS-induced WT mice (Fig. 5A), suggesting that ER stress in LPS-induced ALI may be regulated by ARRB1. Then, we tested the mRNA levels of GRP78 and CHOP in mouse PHMs stimulated with LPS $(0.5 \mu \mathrm{g} / \mathrm{ml})$ stimulation for $6 \mathrm{~h}$, and the results showed higher mRNA levels of GRP78 and CHOP in ARRB1-KO mouse PHMs treated with LPS than in PHMs from WT mice (Fig. 5B, C). To thoroughly define the relationship between ER stress and ARRB1, vector- or ARRB1-overexpressing Raw264.7 and THP-1 cells were stimulated with or without LPS $(1 \mu \mathrm{g} / \mathrm{ml})$. We observed apparently increased levels of GRP78, p-elF2a, CHOP, and ATF4 in the LPS-treated vector cells (Fig. 5D), which implied that ER stress had occurred. However, the trend of the increase was weakened in the LPS-treated ARRB1-overexpressing cells (Fig. $5 D$ ), suggesting that ARRB1 may be a negative regulator of LPSinduced ER stress. Consistently, the mRNA levels of GRP78 and CHOP were enhanced in the Raw264.7 and THP-1 cells challenged with LPS, but this effect was reversed in ARRB1-overexpressing Raw264.7 and THP-1 cells with LPS stimulation (Fig. 5E-H). Overall, ARRB1 notably inhibited LPS-induced ER stress in hepatic macrophages. 
A

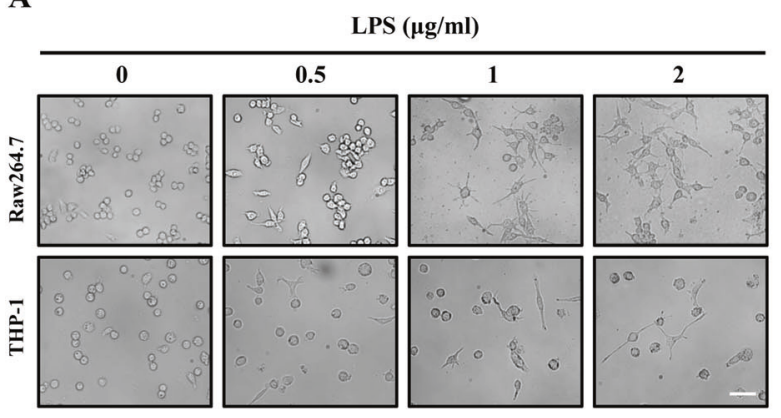

C
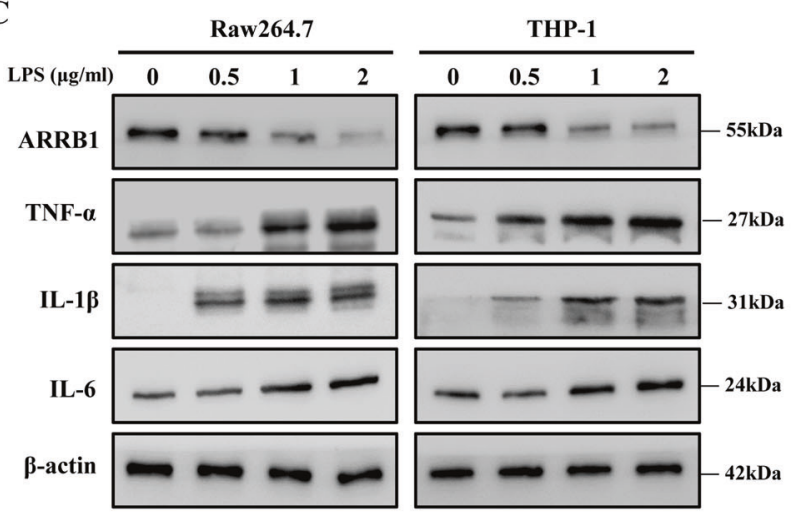

B

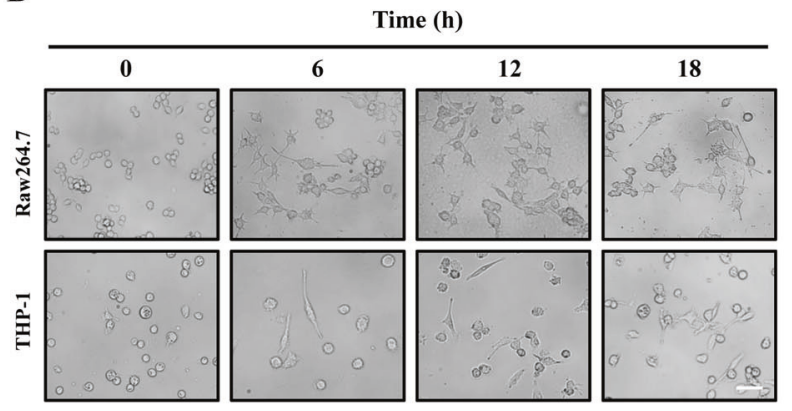

D
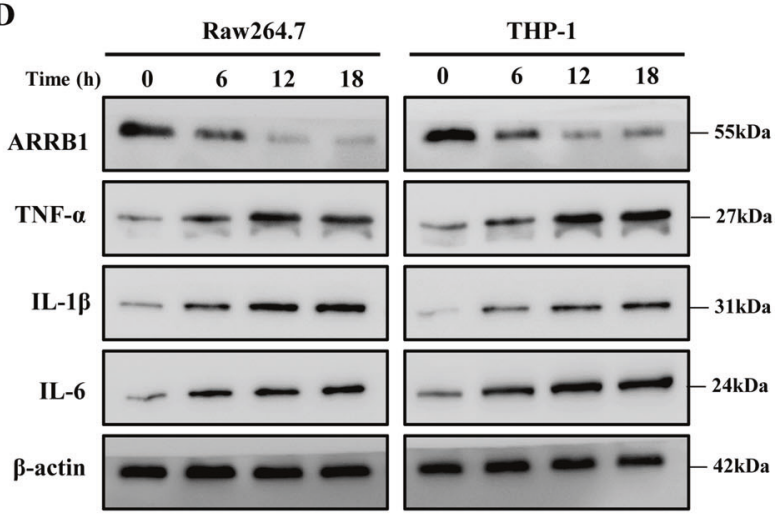

$\mathbf{E}$

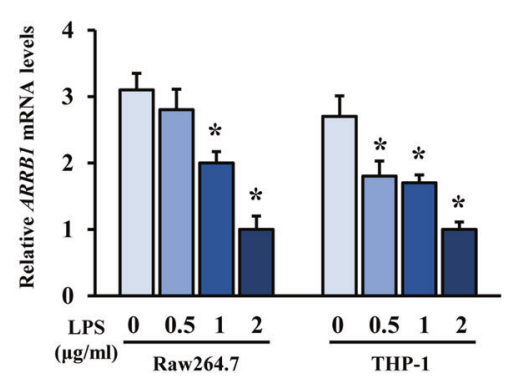

F

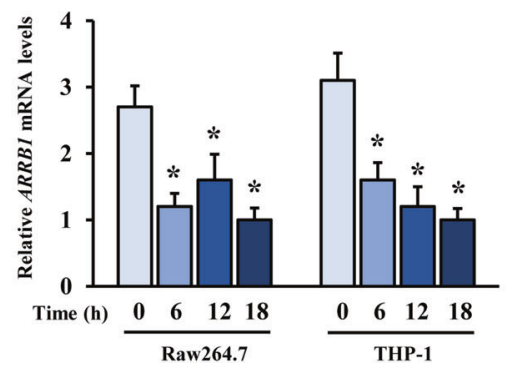

G

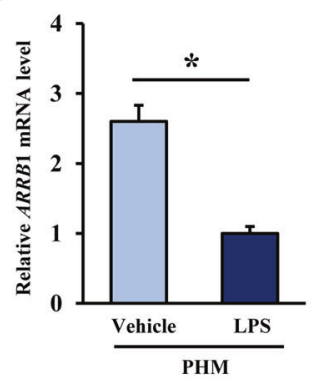

Fig. 2 ARRB1 was involved in LPS-induced activation of liver macrophages. A Representative morphology images of Raw264.7 and THP-1 cells challenged with LPS at the indicated concentration for $6 \mathrm{~h}$ (scale bar: $50 \mu \mathrm{m}$ ). B Representative morphology images of Raw264.7 and THP1 cells treated with LPS $(1 \mu \mathrm{g} / \mathrm{ml})$ were challenged at the indicated times (scale bar: $50 \mu \mathrm{m})$. C Western blotting analysis of ARRB1, TNF- $\alpha$, IL-1 $\beta$, and IL- 6 in cells challenged with LPS at the indicated concentrations for $6 \mathrm{~h}$. $\beta$-Actin was used as the loading control. D Western blotting analysis of ARRB1, TNF- $\alpha, \mathrm{IL}-1 \beta$, and IL- 6 in cells with LPS $(1 \mu \mathrm{g} / \mathrm{ml})$ challenge at the indicated times. E ARRB1 mRNA levels in Raw264.7 and THP- 1 cells were analyzed at the indicated concentration for $6 \mathrm{~h}$ by real-time PCR. ${ }^{*} P<0.05$ compared with LPS $(0 \mu \mathrm{g} / \mathrm{ml})$ treatment by oneway ANOVA. F ARRB1 mRNA levels in Raw 264.7 and THP-1 cells with LPS $(1 \mu \mathrm{g} / \mathrm{ml})$ challenge at the indicated times were analyzed by real-time PCR. ${ }^{*} P<0.05$ compared with vehicle treatment $(0 \mathrm{~h})$ by one-way ANOVA. G ARRB1 mRNA levels in mouse primary hepatic macrophages (PHMs) with LPS $(1 \mu \mathrm{g} / \mathrm{ml})$ challenge for $6 \mathrm{~h}$ were analyzed by real-time PCR. $* P<0.05$ by Student's $t$ test. Data are presented as the mean \pm SD of three separate experiments.

\section{Inhibition of ER stress disturbs ARRB1-modulated activation of liver macrophages in vivo and in vitro}

The preceding data show that ARRB1 suppressed ER stress in LPSinduced ALI and that downregulation of ARRB1 exacerbated LPSinduced activation of liver macrophages. In order to further determine whether ARRB1 regulates LPS-induced activation of liver macrophages through ER stress signaling, WT or ARRB1-KO mice were injected intraperitoneally with LPS $(5 \mathrm{mg} / \mathrm{kg}) 8 \mathrm{~h}$ after being administered with GSK2606414 (GSK414) $(150 \mathrm{mg} / \mathrm{kg}$ ) or vehicle solution by oral gavage. GSK414 is a canonical inhibitor of ER stress that selectively inhibits PERK. Treatment with GSK414 in vivo and in vitro effectively impeded the phosphorylation of PERK [23] and suppressed the activation of the elF2a/ATF4/CHOP signaling pathway (Fig. $6 \mathrm{H}$ ). As expected, the application of GSK
414 obviously ameliorated the disease activity of ALI induced by LPS, even in LPS-induced ARRB1-KO mice (Fig. 6A). Additionally, inhibition of ER stress by GSK414 attenuated F4/80 and MCP-1 accumulation in the livers of LPS-induced WT and ARRB1-KO mice (Fig. 6B-D), implying that ER stress is involved in ARRB1-mediated activation of liver macrophages. Serum ALT and AST levels were reduced in LPS-induced ARRB1-KO mice following GSK414 treatment (Fig. $6 \mathrm{E}, \mathrm{F}$ ), suggesting that suppression of ER stress may alleviate a more severe liver inflammatory response due to $A R R B 1$ deficiency. Furthermore, IHC detection revealed that the inhibition of ER stress in LPS-induced ARRB1-KO mice led to the downregulation of TNF- $\alpha$ and IL-1 $\beta$ (Fig. $6 \mathrm{G}$ ). On the other hand, we found that knockdown of $A R R B 1$ by small interfering RNA (siRNA) enhanced the mRNA and protein expression levels of TNF- 
A

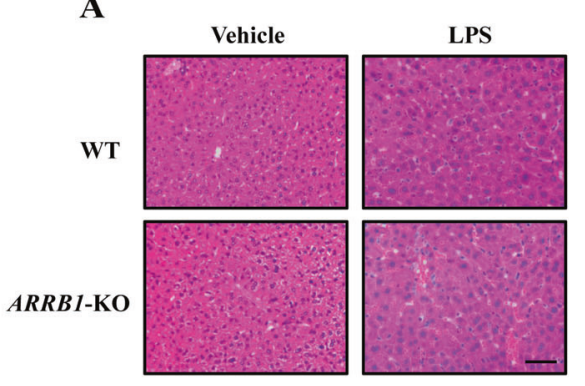

H\&E

C

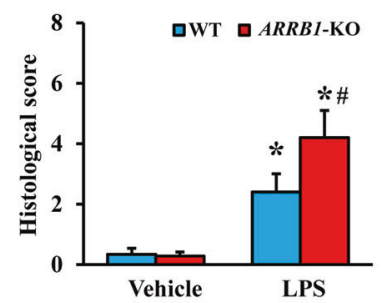

B

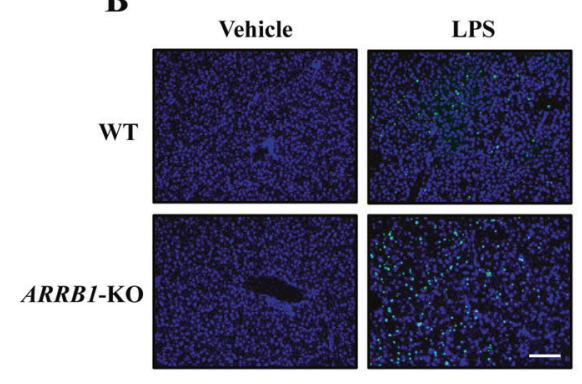

TUNEL

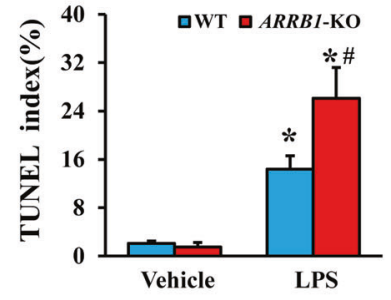

E
D

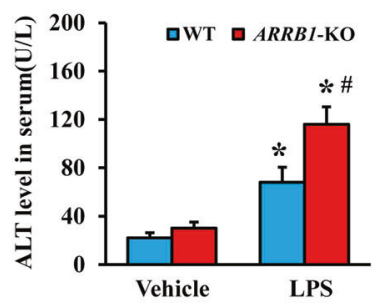

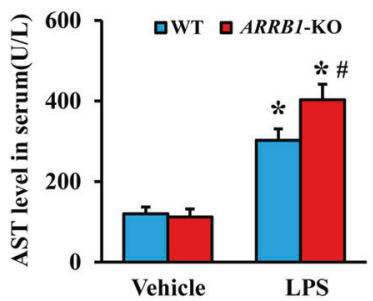

F

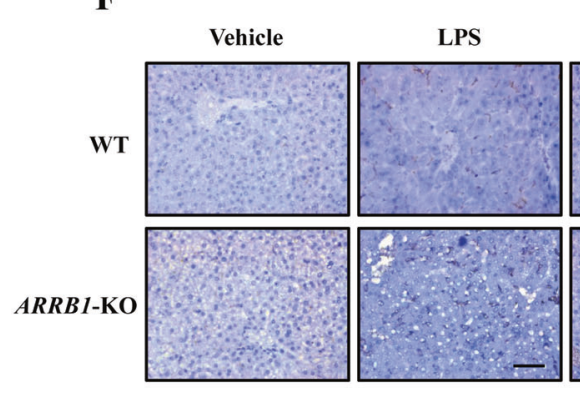

F4/80

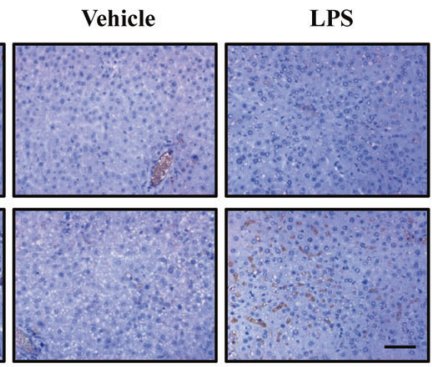

MCP-1

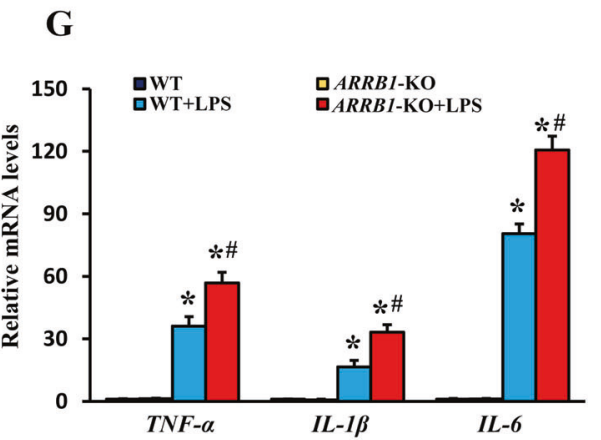

Fig. 3 ARRB1 deficiency aggravated LPS-induced acute liver injury and activation of liver macrophages. A Representative H\&E staining of livers in vehicle- and LPS-induced ARRB1 wild-type (WT) and ARRB1 knockout (KO) mice (scale bar: $50 \mu \mathrm{m}$ ). B TUNEL staining of livers in vehicleand LPS-induced WT and ARRB1-KO mice (scale bar: $50 \mu \mathrm{m}$ ), and the positive TUNEL index was scored. C Liver histology scoring in vehicle- and LPS-induced WT and ARRB1-KO mice. D, E Serum ALT and AST levels in vehicle- and LPS-induced WT and ARRB1-KO mice. F F4/80 and MCP-1 staining of livers in vehicle- and LPS-induced WT and ARRB1-KO mice (scale bar: $50 \mu \mathrm{m}$ ), and the positive F4/80 and MCP-1 indexes were scored. G TNF- $a, I L-1 \beta$, and IL-6 mRNA levels in vehicle- and LPS-induced WT and ARRB1-KO mouse liver tissues were analyzed by real-time PCR. All values are the mean \pm SD ( $n=6$ in each group). ${ }^{*} P<0.05$ compared with the respective vehicle treatment; ${ }^{\#} P<0.05$ compared with LPSinduced WT mice by Student's $t$ test.

a, IL-1 $\beta$, and IL-6 in Raw264.7 and THP-1 cells with LPS treatment, but suppression of ER stress abolished the effect of ARRB1 on LPSinduced activation of liver macrophages (Fig. 6H-J). Together, these results confirmed that ARRB1 regulates the activation of liver macrophages induced by LPS through inhibition of ER stress.

\section{DISCUSSION}

$\mathrm{ALI}$ is a disease caused by multiple etiologies with high morbidity and mortality and is characterized by persistent and excessive inflammatory cascades and serious inflammatory damage to hepatocytes. Among these etiologies such as virus infection and side effects of drug and alcohol abuse, sepsis is a particularly common and severe etiology that leads to multiple organ dysfunction syndromes and poor prognosis [24]. Nevertheless, to date, the mechanism of ALI pathogenesis has not been completely understood. Hence, exploring targeting molecules that involve and determine the occurrence and development of the disease may be helpful for ALI therapy. In this study, we demonstrated that ARRB1 protected against LPSinduced $A L I$ through regulation of macrophage activation via ER stress (Fig. 7).

LPS, a component of gram-negative bacteria, stimulates innate inflammatory and immune responses via pattern recognition receptors, particularly Toll-like receptors (TLRs), and is involved in the pathogenesis of liver injury in patients with severe bacterial infection [6]. Here, we successfully established a mouse model of ALI induced by LPS for the study of sepsis-associated liver injury and observed massive inflammatory cell infiltration in hepatic sinuses with congestion following LPS treatment, along with increased hepatocyte apoptosis and serum ALT and AST. Interestingly, we found that the expression level of ARRB1 was reduced in LPS-induced macrophages. Zeng et al. showed that upregulation of ARRB1 mediated TLR2 activation-induced apoptosis resulting in increased histone $\mathrm{H} 4$ acetylation in bone marrow $\mathrm{CD}_{3} 4^{+}$cells [25]. Moreover, TLR4 and CD44 activation following IL-1 $\beta$ stimulation contributed to downstream ARRB1/NF-KB 
A

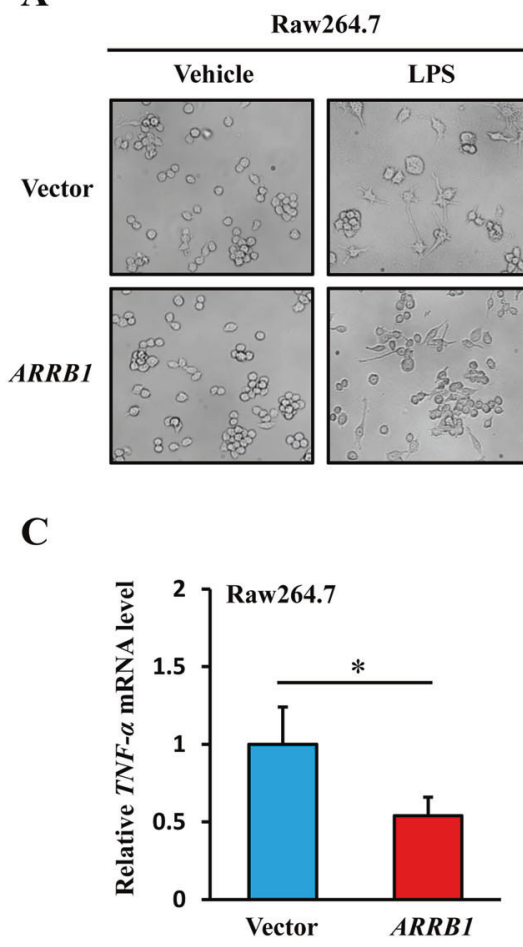

F

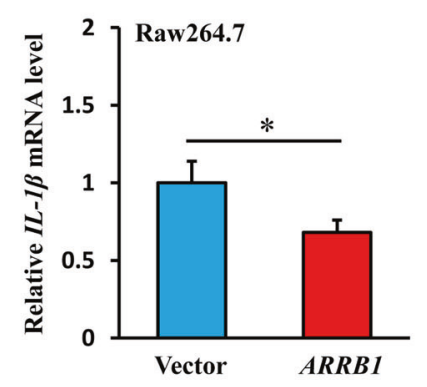

I

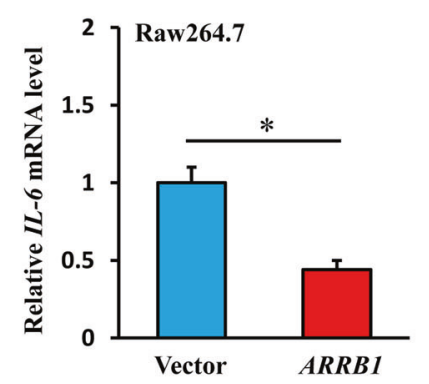

THP-1

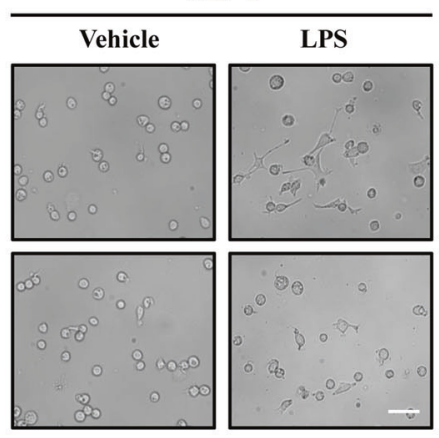

D

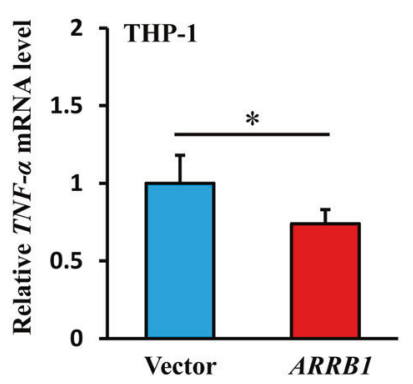

G

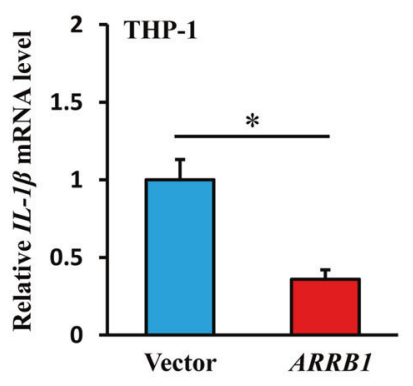

J

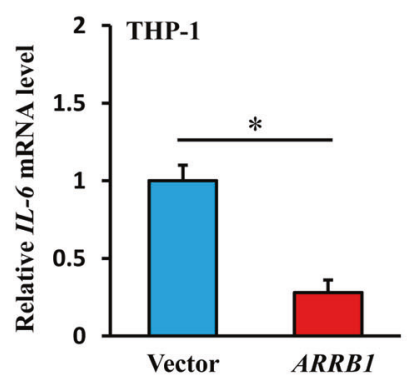

B

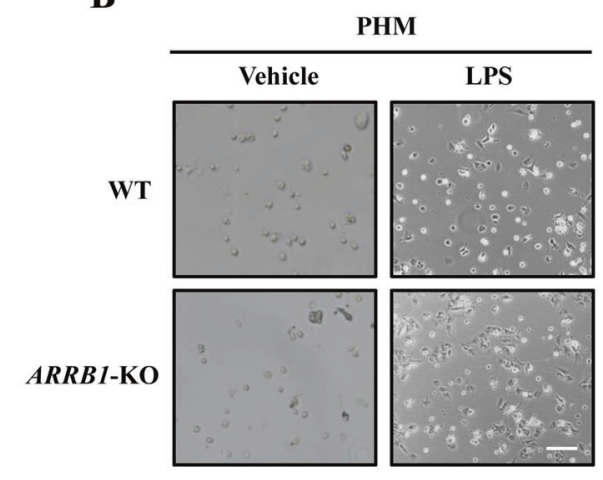

E

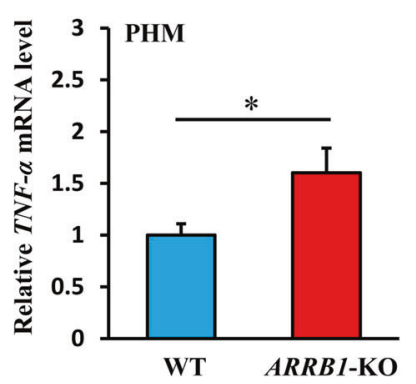

H

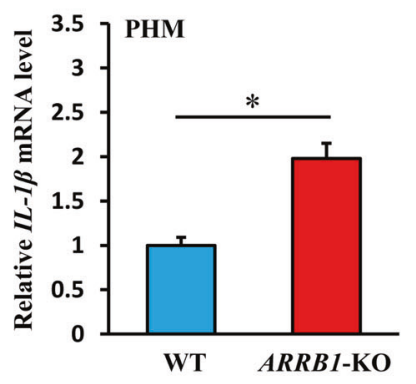

K

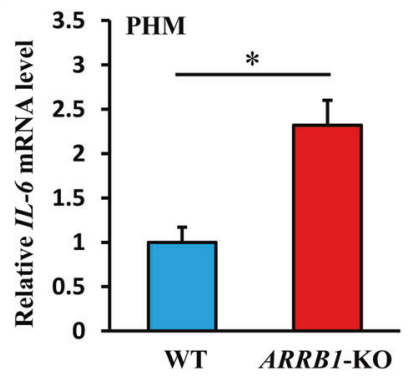

Fig. 4 ARRB1 suppressed the activation of hepatic macrophages induced by LPS. A Representative morphology images of vector- and ARRB1-overexpressing Raw264.7 and THP-1 cells with LPS $(1 \mu \mathrm{g} / \mathrm{ml})$ challenge for $6 \mathrm{~h}$ by an inverted microscope (scale bar: $50 \mu \mathrm{m}$ ). B Representative morphology images of WT and ARRB1-KO mouse primary hepatic macrophages with LPS $(0.5 \mu \mathrm{g} / \mathrm{ml})$ were challenged for $6 \mathrm{~h}$ (scale bar: $50 \mu \mathrm{m})$. C-K TNF- $a, I L-1 \beta$, and IL-6 mRNA levels in vector- and ARRB1-overexpressing Raw264.7 and THP-1 cells with LPS (1 $\mu \mathrm{g} / \mathrm{ml})$ challenge for $6 \mathrm{~h}$ and mouse primary hepatic macrophages with LPS $(0.5 \mu \mathrm{g} / \mathrm{ml})$ challenge for $6 \mathrm{~h}$ were analyzed by real-time PCR. Data are presented as the mean \pm SD of three separate experiments. ${ }^{*} P<0.05$ by Student's $t$ test.

activation and inflammatory mediator transcription [26]. These evidences suggest that TLRs may provide research clues to explain the effects of LPS on ARRB1 in different cells.

Actually, existing studies have reported that ARRB1 not only responds to the termination of G-protein activation as a classic adaptor protein but also participates in the mediation of the inflammatory response through multiple signal transduction pathways. Preceding research from our team revealed that ARRB1 alleviated acute pancreatitis via repression of NF-kBp65 activation [27]. A recent study showed that ARRB1 inhibited nonalcoholic steatohepatitis progression by promoting growth differentiation factor 15 maturation [28]. These studies indicate that ARRB1 
$\mathbf{A}$
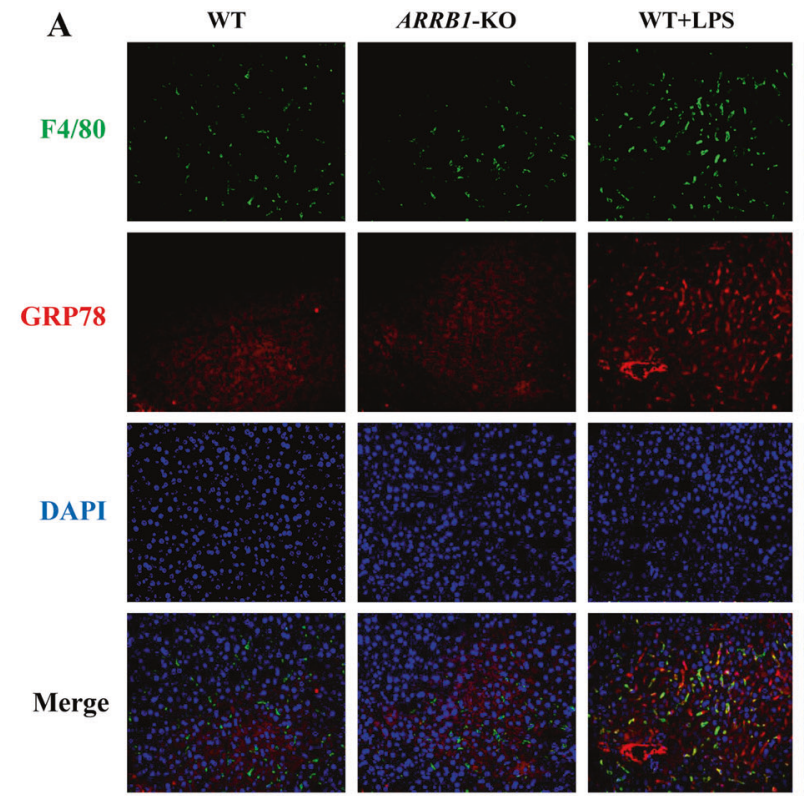

ARRB 1-KO+LPS
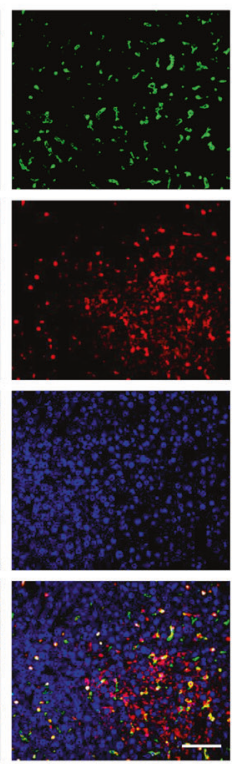

B

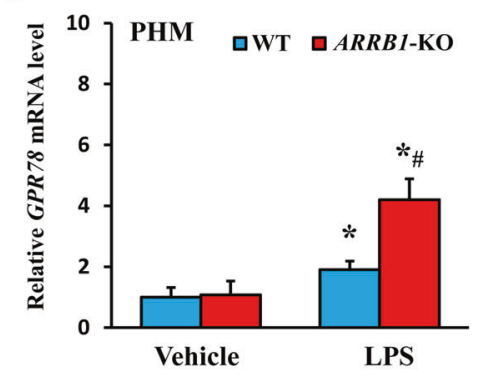

C

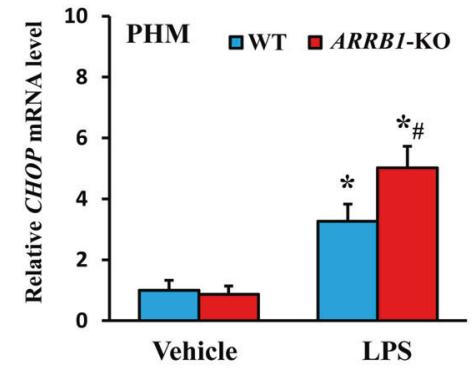

D

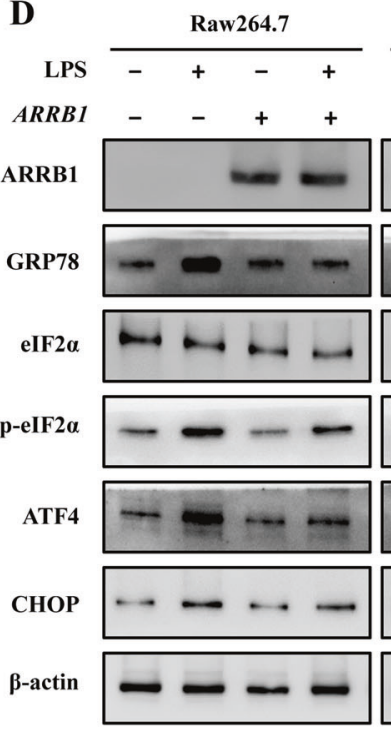

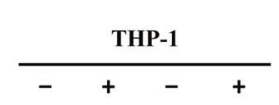
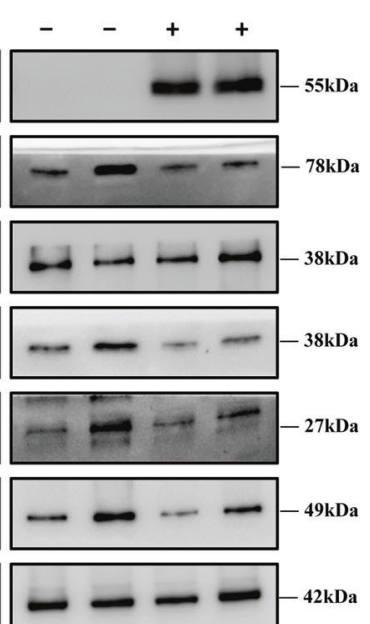

$\mathbf{E}$

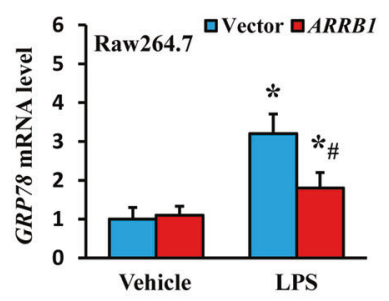

G

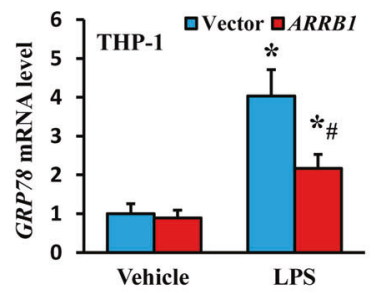

F

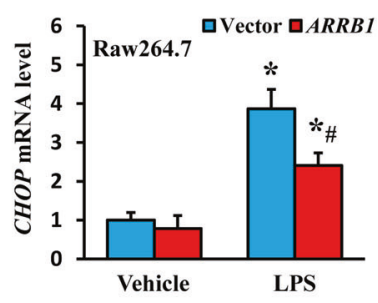

H

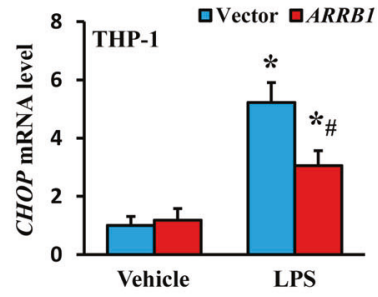

Fig. 5 Overexpression of ARRB1 suppressed LPS-induced ER stress in hepatic macrophages. A Double immunofluorescent staining for F4/ 80 and GRP78 in the indicated mouse liver sections. Nuclei were stained with DAPI in blue. F4/80 was stained green, and GRP78 was visualized red. The merged positive signals of F4/80 and GRP78 are visualized in yellow (scale bar: $50 \mu \mathrm{m}$ ). B, C GRP78 and CHOP mRNA levels in primary hepatic macrophages with LPS $(0.5 \mu \mathrm{g} / \mathrm{ml})$ challenge for $6 \mathrm{~h}$ from WT and ARRB1-KO mice were analyzed by real-time PCR. ${ }^{*} P<0.05$ compared with the respective vehicle treatment; ${ }^{\#} P<0.05$ compared with LPS-induced WT mice by Student's $t$ test. D Protein expression levels of ARRB1, GRP78, elF2 $\alpha$, p-elF $2 \alpha$, CHOP, and ATF4 in ARRB1-overexpressing Raw264.7 and THP-1 cells with or without LPS (1 $\mu \mathrm{g} / \mathrm{ml}) \mathrm{challenge}$ for $6 \mathrm{~h}$. E-H GRP78 and CHOP mRNA levels of ARRB1-overexpressing Raw264.7 and THP-1 cells with LPS ( $1 \mu \mathrm{g} / \mathrm{ml})$ were challenged for $6 \mathrm{~h}$ and analyzed by real-time PCR. ${ }^{*} P<0.05$ compared with the respective vehicle treatment; ${ }^{\#} P<0.05$ compared with vector cells following LPS treatment by Student's $t$ test. Data are presented as the mean \pm SD of three separate experiments.

directly or indirectly regulates inflammatory responses in various disease models. In this study, we found that the absence of ARRB1 exacerbated the activation of hepatic macrophages, accounting for disordered inflammatory cascades and more severe AKI. On the other hand, in previous studies, we found that the expression level of ARRB1 was enhanced in the livers of mice intraperitoneally injected with $\mathrm{CCl} 4$ or diethylnitrosamine (DEN) to induce AKI and that TNF-a stimulation facilitated ARRB1 expression in hepatocytes [15]. Here, we discovered that ARRB1 modulated the release of proinflammatory cytokines including TNF- $\alpha$, IL- $1 \beta$, and IL- 6 in hepatic macrophages, which means that ARRB1-mediated release of inflammatory cytokines, in turn, may regulate ARRB1 expression. Consistently, ARRB1 is a protective factor in $\mathrm{CCl}_{4}$ or DENinduced AKI as well as LPS-induced AKI. Hence, combined with previous studies, we hypothesized that ARRB1 has different functions in hepatocytes and macrophages in LPS-induced AKI. In fact, ARRB1 is also removed from hepatocytes in ARRB1-KO mice, and a lack of ARRB1 blocks the proliferation of liver cells in inflammation-mediated hepatocellular carcinogenesis [15]. In this research, we also found that the lack of ARRB1 aggravated hepatocyte apoptosis, which may not be due only to the damage we found caused by inflammatory cytokines. Given this 
A

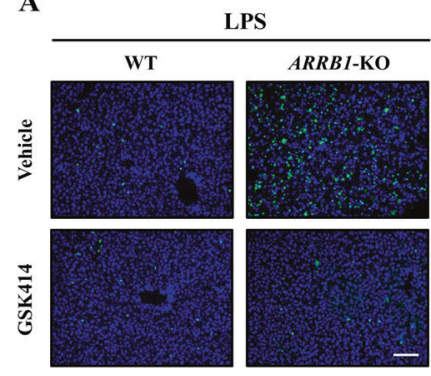

TUNEL
B

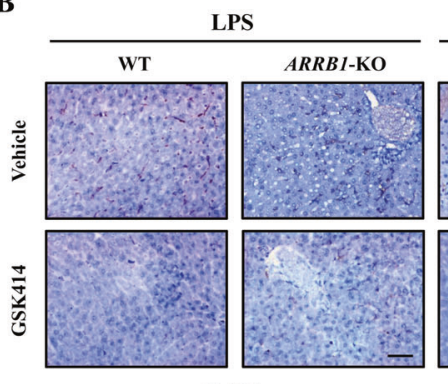

$\mathbf{F 4 / 8 0}$

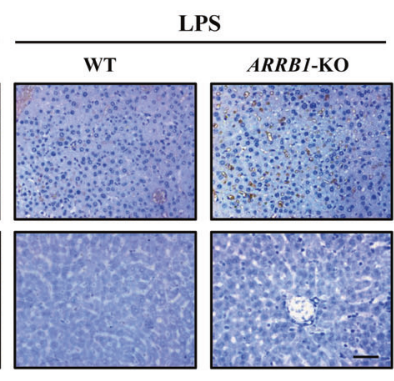

MCP-1
C

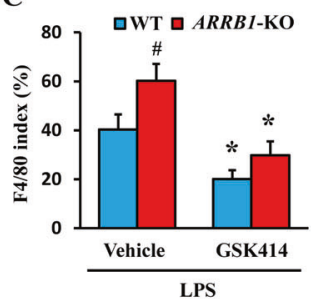

D

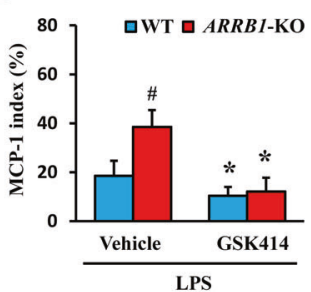

$\mathbf{E}$

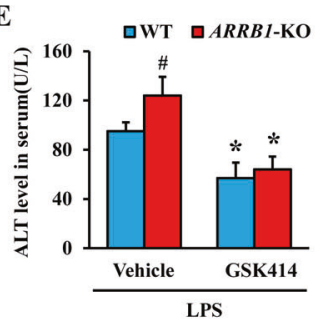

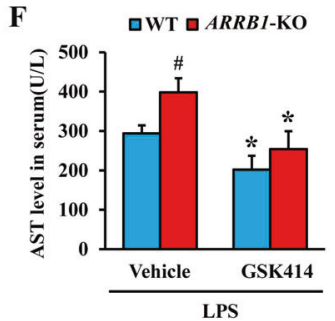

G
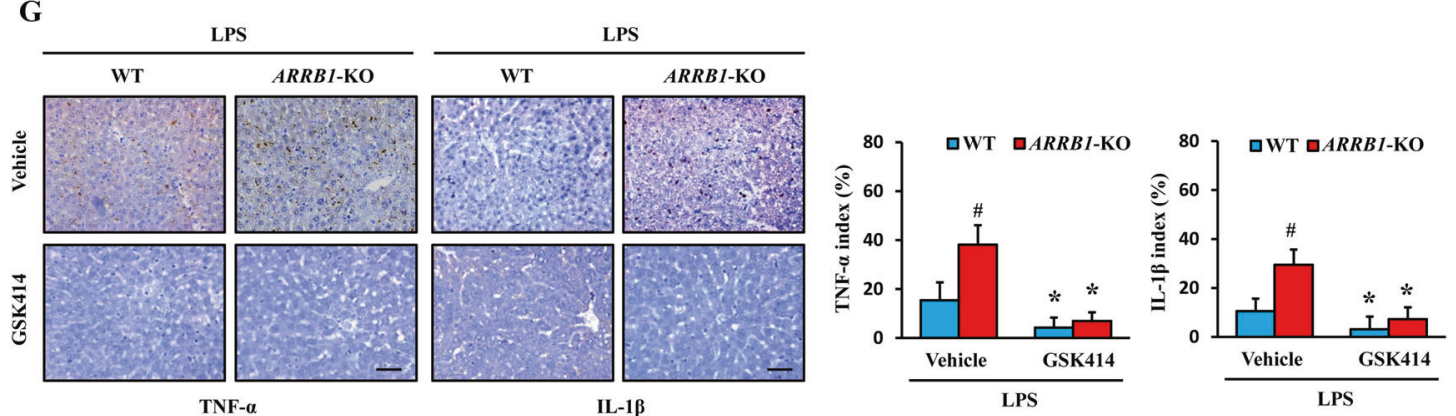

H

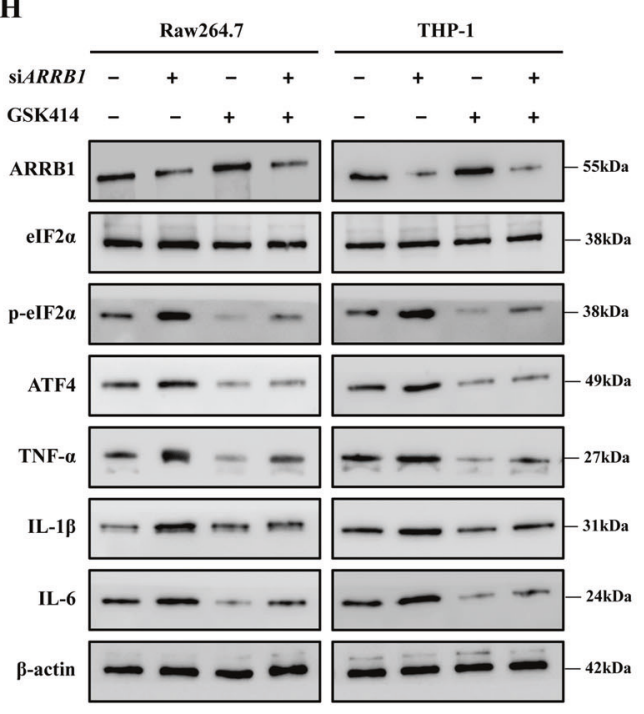

information, the role of ARRB1 in hepatocytes and its influence on ALK deserve further investigation.

Activation of macrophages is mediated by signaling cascades downstream of TLR and cytokine receptors, such as PI3K/Akt, NF$K B$, and mitogen-activated protein kinase signaling [29]. Most G-

I
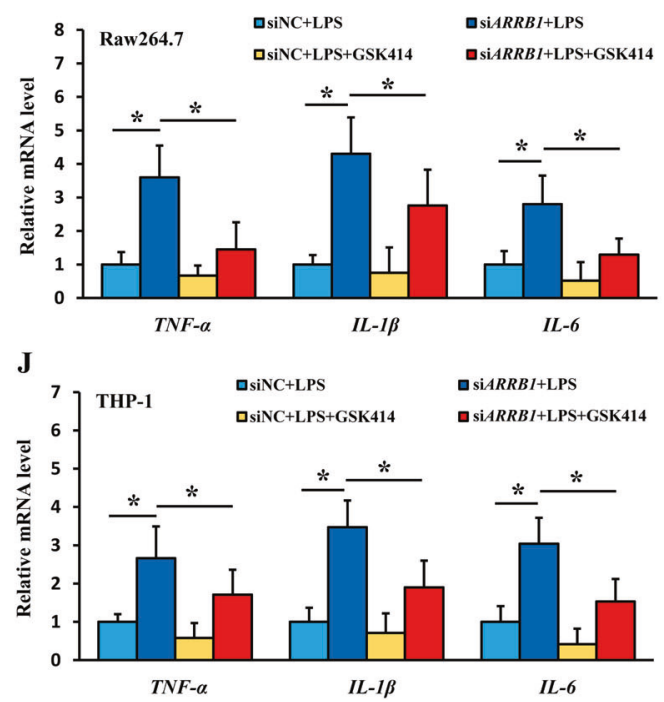

protein-mediated signal-transduction pathways are deemed to be relevant to the stimulation of macrophages by activators or immunomodulators [30]. ER stress is well described as a crucial mediator of inflammatory injury and triggers macrophage activation and even hepatocyte apoptosis if the inflammatory 
Fig. 6 Blockage of ER stress abrogated ARRB1-modulated activation of liver macrophages in vivo and in vitro. Mice were intraperitoneally administered LPS injection $(5 \mathrm{mg} / \mathrm{kg}) 8 \mathrm{~h}$ after gavage with GSK414 $(150 \mathrm{mg} / \mathrm{kg})$ or vehicle solution. $n=6$ in each group. A TUNEL staining of livers in LPS-induced mice with or without GSK414 challenge (scale bar: $100 \mu \mathrm{m}$ ). B-D F4/80 and MCP-1 staining of livers in LPS-induced mice with or without GSK414 challenge (scale bar: $50 \mu \mathrm{m}$ ), and the positive F4/80 and MCP-1 indexes were scored. E, F Serum ALT and AST levels in LPS-induced mice with or without GSK414 challenge. G TNF- $\alpha$ and IL-1 $\beta$ staining of livers in LPS-induced mice with or without GSK414 challenge (scale bar: $50 \mu \mathrm{m}$ ), and the positive TNF- $\alpha$ and IL-1 $\beta$ indexes were scored. $\mathbf{C}-\mathbf{G} * P<0.05$ compared with the respective vehicle treatment; ${ }^{\#} P<0.05$ compared with LPS-induced WT mice by Student's $t$ test. H-J Raw264.7 and THP-1 cells were challenged with LPS ( $1 \mu$ g/ $\mathrm{ml}$ ) for $6 \mathrm{~h}$ with or without GSK414 (1 $\mu \mathrm{M})$ treatment after knockdown of ARRB1 by siRNA. $\mathbf{H}$ Western blotting analysis of the indicated protein expression. I, J TNF- $a, I L-1 \beta$, and IL-6 mRNA levels in Raw264.7 and THP-1 cells in the indicated treatments were analyzed by real-time PCR. * $P<$ 0.05 by Student's $t$ test. Data are presented as the mean \pm SD of three separate experiments.

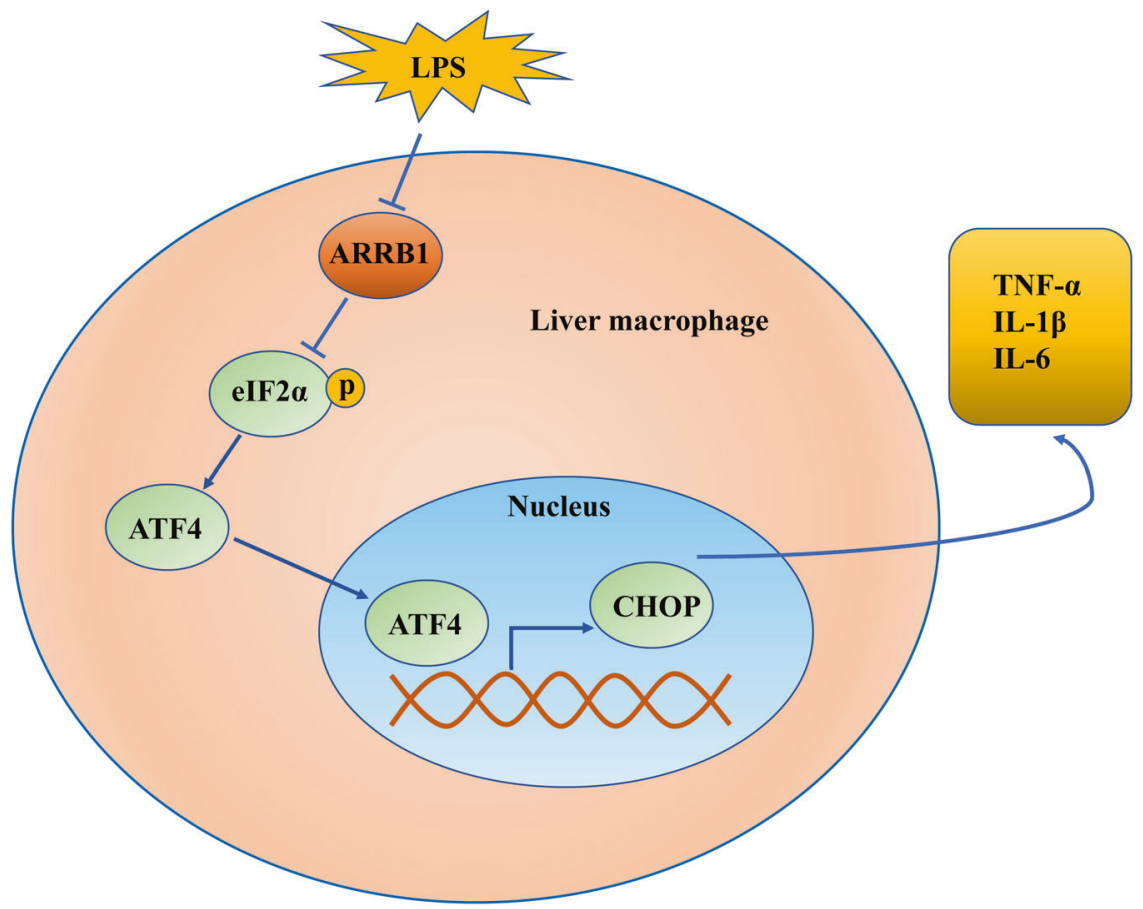

Fig. 7 Summary of the proposed regulatory mechanism of ARRB1 in this study. ARRB1 suppresses LPS-induced release of inflammatory cytokines in response to activated macrophages. ARRB1 regulates the ER stress signaling pathway by inhibiting the phosphorylation of elF2 $\alpha$ and downstream ATF4 and CHOP expression in liver macrophages.

injury continuously exists. To verify whether this triggering of macrophage activation and even hepatocyte apoptosis also occurred in LPS-induced ALI, we administered GSK414, a specific inhibitor of ER stress, in vivo and in vitro, and consistent with previous studies, our results showed that the application of GSK414 effectively suppressed ER stress and subsequent macrophage activation by preventing the activation of the elF2a/ATF4/ CHOP signaling pathway. Moreover, we confirmed that ER stress was an indispensable modulator of ARRB1-mediated suppression of macrophage activation. However, blocking ER stress did not affect the expression level of ARRB1, though interference with ARRB1 attenuated ER stress. Additionally, a previous study found that ARRB1 restrained upregulated ER stress/p53 via repressing $\mathrm{p}$ p65/inducible nitric oxide synthase in portal hypertensive gastropathy [16]. Indeed, genetic abnormalities and the aberrant inflammatory microenvironment of the liver respond to the induction of ER stress in macrophages of ALI. Abundant genetic studies have revealed primary aberrances in several ER homeostasis-associated genes, such as carboxylesterase 2, sirtuin 1 , and interferon regulatory factor 3 , in AKI patients [31-33]. Combined with preceding studies from our team, ARRB1 may be a potential ER homeostasis-associated gene.

In conclusion, our findings revealed that ARRB1 deficiency aggravated LPS-induced ALI resulting from excessive activation of macrophages. Blocking ER stress abolished more severe macrophage activation and exacerbated ALI due to ARRB1 downregulation. In brief, ARRB1 suppresses the activation of hepatic macrophages via regulating ER stress in LPS-induced ALI, and ARRB1, especially ARRB1-mediated ER stress may be a promising therapeutic target for ALI.

\section{MATERIALS AND METHODS}

\section{Treatment of mice}

All animal experiments in this study were conducted with the approval of the Institutional Animal Care and Use Committee at Third Affiliated Hospital of Sun Yat-Sen University. ARRB1-KO mice were gifts from Dr. Robert J Lefkowitz, Duke University Medical Center, Durham, NC, USA. All ARRB1-WT and ARRB1$\mathrm{KO}$ mice bred on a C57BL/6 background were generated by heterozygote intercrosses. The mice were housed in microisolator cages under controlled conditions at room temperature with $50 \%$ humidity and a 12-/12-h light-dark cycle (lights on at 8:00 a.m.) with food and sterilized water ad libitum. To establish the ALI model, overnight fasting 6-week-old male mice were intraperitoneally injected with LPS (Sigma, St. Louis, MO) at $5 \mathrm{mg} / \mathrm{kg}$. In the control trial, mice were intraperitoneally injected with the same volume of physiological saline. To inhibit ER stress in vivo, 6-week-old male mice were administered GSK414 (Selleck, Shanghai, China) suspended in vehicle solution containing $0.5 \%$ hydroxypropyl methylcellulose and $0.1 \%$ Tween- 80 in water at $\mathrm{pH} 4.8(150 \mathrm{mg} / \mathrm{kg}$ body weight) by oral gavage $8 \mathrm{~h}$ before intraperitoneal injection of LPS ( $5 \mathrm{mg} / \mathrm{kg}$ ). The control mice were injected only with an equal dose of LPS. The mice were sacrificed $6 \mathrm{~h}$ later through carbon dioxide inhalation used as the method of euthanasia. 
10

Table 1. Primer sequences used in real-time PCR analysis.

\begin{tabular}{|c|c|}
\hline Human & Primer sequences \\
\hline ARRB1 & $\begin{array}{l}\text { 5'-GCGAGCACGCTTACCCTTTT-3' (sense) } \\
\text { 5'-CAAGCCTTCCCCGTGTCTTC-3' (antisense) }\end{array}$ \\
\hline$T N F-a$ & $\begin{array}{l}\text { 5'-GTTCCTCAGCCTCTTCTCCT-3' (sense) } \\
\text { 5'-ACAACATGGGCTACAGGCTT-3' (antisense) }\end{array}$ \\
\hline$I L-1 \beta$ & $\begin{array}{l}\text { 5'-TCCCCAGCCCTTTTGGTTGA-3' (sense) } \\
\text { 5'-TTAGAACCAAATGTGGCCGTG-3' (antisense) }\end{array}$ \\
\hline IL-6 & $\begin{array}{l}\text { 5'-ATGTCTGAGGCTCATTCTGC-3' (sense) } \\
5^{\prime} \text {-GCGGCTACATCTTTGGAATC-3' (antisense) }\end{array}$ \\
\hline GRP78 & 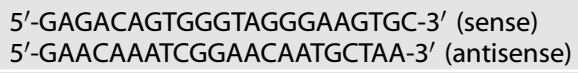 \\
\hline $\mathrm{CHOP}$ & $\begin{array}{l}\text { 5'-CCACTCTTGACCCTGCTTC-3' (sense) } \\
\text { 5'-CCACTCTGTTTCCGTTTCC-3' (antisense) }\end{array}$ \\
\hline$\beta$-actin & $\begin{array}{l}\text { 5'-GTCTTCCCCTCCATCGTG-3' (sense) } \\
\text { 5'-AGGGTGAGGATGCCTCTCTT-3' (antisense) }\end{array}$ \\
\hline Mouse & Primer sequences \\
\hline$A R R B 1$ & $\begin{array}{l}\text { 5'-CCGAGGACAAGAAGCCACTGA-3' (sense) } \\
5^{\prime} \text {-AGAGTGACTGAGCATGGAAGGT-3' (antisense) }\end{array}$ \\
\hline$T N F-a$ & $\begin{array}{l}\text { 5'-CTTCATCACCTATCCCTCGAC-3' (sense) } \\
5^{\prime} \text {-CTGGCTATTTGCTTCTTGTCCT-3' (antisense) }\end{array}$ \\
\hline$I L-1 \beta$ & 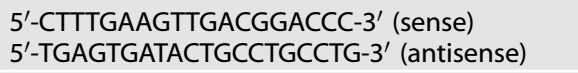 \\
\hline IL-6 & $\begin{array}{l}\text { 5'-TTGTGCAATGGCAATTCTGA-3' (sense) } \\
\text { 5'-CGGACTCTGGCTTTGTCTTTCT-3' (antisense) }\end{array}$ \\
\hline GRP78 & $\begin{array}{l}\text { 5'-GCCGAGGAGGAGGACAAGAA-3' (sense) } \\
\text { 5'-ACACACCGACGCAGGAATAG-3' (antisense) }\end{array}$ \\
\hline $\mathrm{CHOP}$ & $\begin{array}{l}\text { 5'-CCCTCGCTCTCCAGATTCC-3' (sense) } \\
5^{\prime} \text {-TCTCCTTCATGCGTTGCTT-3' (antisense) }\end{array}$ \\
\hline$\beta$-actin & $\begin{array}{l}\text { 5'-GGCTGTATTCCCCTCCATCG-3' (sense) } \\
\text { 5'-CCAGTTGGTAACAATGCCATGT-3' (antisense) }\end{array}$ \\
\hline
\end{tabular}

Cell culture and treatment

Cell lines were purchased from the American Type Culture Collection. Raw264.7 cells were cultured in Dulbecco's modified Eagle's medium (DMEM) (Gibco BRL, Rockville, MD, USA) containing 10\% heat-inactivated fetal bovine serum (FBS). THP-1 cells were cultured in RPMI-1640 medium (Gibco BRL, Rockville, MD, USA) containing 10\% FBS and $0.05 \mathrm{mM}$ $\beta$-mercaptoethanol (Sigma, St. Louis, MO). To induce THP-1 cell differentiation into macrophages, phorbol 12-myristate 13-acetate (Selleck, Shanghai, China, $10 \mathrm{ng} / \mathrm{ml}$ ) was added to THP-1 cells for $48 \mathrm{~h}$ before other treatments. All cells were cultured in an incubator with $5 \% \mathrm{CO}_{2}$ at $37^{\circ} \mathrm{C}$. For drug intervention, Raw264.7 cells and THP-1 cells were treated with the indicated concentration of LPS (Sigma, St. Louis, MO), with or without $1 \mu \mathrm{M}$ GSK414 (Selleck, Shanghai, China) for the indicated times.

\section{Establishment of cell lines and interference with ARRB1}

$A R R B 1$-overexpressing lentiviruses were purchased from GeneChem (Shanghai, China). To establish stable ARRB1-overexpressing Raw264.7 cells and THP-1 cell lines, we infected the cells with the ARRB1 lentivirus according to the instructions and Raw264.7 cells and THP-1 cells were selected by puromycin $(2 \mu \mathrm{g} / \mathrm{ml})$. To silence the ARRB1 gene, ARRB1 siRNA was transfected into cells according to the instructions of Lipofectamine 3000 (Thermo Fisher Scientific, USA). The ARRB1 siRNA sequence was 5'GTCACCAACAACACCAACA-3' (Gene Pharma, China).

\section{RNA extraction and real-time PCR for gene expression}

For quantitative real-time PCR, total RNA was extracted from freshly frozen liver tissues or cells by TRIzol (Promega, Madison, WI, USA), and then firststrand complementary DNA synthesis was performed by a Reverse Transcription Kit (TOYOBO, Japan) according to the manufacturer's instructions. The mRNA levels of relevant genes were detected by a Mini Opticon Real-time PCR System (Bio-Rad, Hercules, CA, USA) with SYBR Green (Invitrogen, USA). $\beta$-Actin was used as a normalized control in the expression level analysis of relevant genes. Primer sequences of relevant genes are provided in Table 1.

\section{Protein extraction and Western blot}

Total proteins were extracted from fresh cell lysates by RIPA buffer and examined by Western blot. Antibodies against ARRB1 (Cell Signaling Technology, 12697), GRP78 (Cell Signaling Technology, 3177), elF2a (Cell Signaling Technology, 5324), p-elF2a (Cell Signaling Technology, 3398), CHOP (Cell Signaling Technology, 2895), TNF-a (Abclonal, A11534), IL-1 $\beta$ (Abclonal, A19635), IL-6 (Abclonal, A0286), and $\beta$-actin (Sigma-Aldrich, A5441) were used as primary antibodies. ECL chemiluminescence (Thermo Fisher Scientific, Waltham, MA, USA) was used for signal visualization analysis. $\beta$-Actin was used as a normalized control in the expression level analysis of each target protein.

\section{Analysis of apoptosis}

TUNEL staining was performed using the TUNEL Apoptosis Assay Kit (Beyotime, Shanghai, China) according to the manufacturer's instructions. The apoptotic index was calculated by dividing the number of apoptotic cells by the total number of cells in the livers of at least 20 randomly selected fields $(\times 200)$. Six mice from each group were studied.

\section{IHC and immunofluorescent staining}

For histological analysis, formalin-fixed liver tissues were embedded in paraffin, and $3 \mathrm{~mm}$ histological sections obtained from paraffin-embedded liver tissues were subjected to $\mathrm{H} \& \mathrm{E}$ and $\mathrm{IHC}$ staining. Liver sections were incubated with $3 \%$ hydrogen peroxide to eliminate endogenous peroxidase activity. Antigen was retrieved in boiling EDTA buffer ( $\mathrm{pH}$ 8.0) under high temperature and pressure for $3 \mathrm{~min}$. For IHC staining, primary antibodies against F4/80 (Cell Signaling Technology, 70076), MPO (Abcam, ab208670), TNF-a (Abclonal, A11534), IL-1 $\beta$ (Abclonal, A19635), and MCP-1 (Abclonal, A7277) were used. For double immunofluorescence staining, sections were simultaneously incubated with primary antibodies against F4/80 (rabbit monoclonal, Cell Signaling Technology, 70076) and GRP78 (mouse monoclonal, Proteintech, 66574). Specific Alexa 488 (A11008) and Alexa 594 (A11032) fluorescence-conjugated secondary antibodies (Invitrogen) were used in the dark, and 4',6-diamidino-2-phenylindole (Invitrogen, D1306) was used to stain the cell nuclei. Images were analyzed using a fluorescence microscope.

\section{Histopathology scoring of liver injury}

Liver tissues were fixed and embedded, and the sections were subjected to $\mathrm{H} \& \mathrm{E}$ staining for subsequent histological assessment. Histological scores were evaluated blindly based on the degree of hemorrhage as previously described [20] in ten randomly magnified fields $(\times 200)$. Six mice from each group were studied.

\section{Serum ALT and AST measurements}

Serum ALT and AST levels were determined in mouse serum using ALT and AST Detection Kits (Kehua Biology, Shanghai, China) by an automatic biochemical analyzer.

\section{Isolation of PHMs}

The protocol of isolation of murine PHMs was performed according to previous reports [20]. The livers of mice were perfused in situ with collagenase type IV (Sigma-Aldrich, St. Louis, MO, USA) until liver cells could easily be stripped from the liver capsule. The digested liver tissues were passed through a $100-\mathrm{mm}$ mesh filter to gain a cell suspension. Next, the cell suspension was centrifuged at $50 \times \mathrm{g} / \mathrm{min}$ for $1 \mathrm{~min}$, and the supernatant was collected for subsequent isolation. Nonparenchymal cells were isolated at the interface in a discontinuous gradient of 25 and $50 \%$ Percoll (Solarbio, Beijing, China) in phosphate-buffered saline salt solution and plated in 24-well plates. Nonadherent cells were removed by replacing the fresh culture medium $1 \mathrm{~h}$ later to eliminate other nonparenchymal cells and purify PHMs. Adherent macrophages were continuously cultured with DMEM containing $10 \% \mathrm{FBS}, 100 \mathrm{U} / \mathrm{ml}$ penicillin, and $0.1 \mathrm{mg} / \mathrm{ml}$ streptomycin (Gibco BRL, Rockville, MD, USA). The cells followed by the indicated drug treatment were photographed by an inverted microscope.

\section{Statistical analyses}

All results were expressed as the mean $\pm S D$. The data were analyzed using SPSS 22.0 and Microsoft Excel. Normal distribution was assumed with regard to small sample sizes. To compare the differences of groups, a twotailed Student's $t$ test or one-way analysis of variance was applied. 
Differences were considered to be statistically significant when $P<0.05$. All trials were individually repeated at least twice with consistent results.

\section{DATA AVAILABILITY}

The datasets used and/or analyzed during the current study are available from the corresponding author on reasonable request.

\section{REFERENCES}

1. Shi $Y$, Yang $Y$, Hu $Y$, Wu W, Yang $Q$, Zheng $M$, et al. Acute-on-chronic liver failure precipitated by hepatic injury is distinct from that precipitated by extrahepatic insults. Hepatology. 2015;62:232-42.

2. Jalan R, Moreau R, Arroyo V. Acute-on-chronic liver failure. Reply. N Engl J Med. 2020;383:893-4.

3. Kim SJ, Lee SM. NLRP3 inflammasome activation in D-galactosamine and lipopolysaccharide-induced acute liver failure: role of heme oxygenase-1. Free Radic Biol Med. 2013;65:997-1004.

4. Liu $F$, Zhang $X$, Ling $P$, Liao J, Zhao M, Mei L, et al. Immunomodulatory effects of xanthan gum in LPS-stimulated RAW 264.7 macrophages. Carbohydr Polym. 2017;169:65-74.

5. Wynn TA, Chawla A, Pollard JW. Macrophage biology in development, homeostasis and disease. Nature. 2013;496:445-55.

6. Decker K. Biologically active products of stimulated liver macrophages (Kupffer cells). Eur J Biochem. 1990;192:245-61.

7. Ito $S$, Tanaka $Y$, Oshino $R$, Okado $S$, Hori M, Isobe Kl. GADD34 suppresses lipopolysaccharide-induced sepsis and tissue injury through the regulation of macrophage activation. Cell Death Dis. 2016;7:e2219.

8. Huang $X$, Liu $Y$, Lu Y, Ma C. Anti-inflammatory effects of eugenol on lipopolysaccharide-induced inflammatory reaction in acute lung injury via regulating inflammation and redox status. Int Immunopharmacol. 2015;26:265-71.

9. Kang J, Shi Y, Xiang B, Qu B, Su W, Zhu M, et al. A nuclear function of betaarrestin 1 in GPCR signaling: regulation of histone acetylation and gene transcription. Cell. 2005;123:833-47.

10. DeWire SM, Ahn S, Lefkowitz RJ, Shenoy SK. Beta-arrestins and cell signaling. Annu Rev Physiol. 2007;69:483-510.

11. Shukla AK, Xiao K, Lefkowitz RJ. Emerging paradigms of beta-arrestin-dependent seven transmembrane receptor signaling. Trends Biochem Sci. 2011;36:457-69.

12. Ke P, Shao BZ, Xu ZQ, Chen XW, Wei W, Liu C. Activating alpha7 nicotinic acetylcholine receptor inhibits NLRP3 inflammasome through regulation of betaarrestin-1. CNS Neurosci Ther. 2017;23:875-84.

13. Chu $\mathrm{CH}$, Chen SH, Wang Q, Langenbach R, Li H, Zeldin D, et al. PGE2 inhibits IL-10 production via EP2-mediated beta-arrestin signaling in neuroinflammatory condition. Mol Neurobiol. 2015;52:587-600.

14. Sharma D, Packiriswamy N, Malik A, Lucas PC, Parameswaran N. Nonhematopoietic beta-Arrestin-1 inhibits inflammation in a murine model of polymicrobial sepsis. Am J Pathol. 2014;184:2297-309.

15. Yang Y, Guo Y, Tan S, Ke B, Tao J, Liu H, et al. beta-Arrestin1 enhances hepatocellular carcinogenesis through inflammation-mediated Akt signalling. Nat Commun. 2015;6:7369.

16. Tan S, Li L, Chen T, Chen X, Tao L, Lin X, et al. beta-Arrestin-1 protects against endoplasmic reticulum stress/p53-upregulated modulator of apoptosis-mediated apoptosis via repressing p-p65/inducible nitric oxide synthase in portal hypertensive gastropathy. Free Radic Biol Med. 2015;87:69-83.

17. Diaz-Bulnes P, Saiz ML, Lopez-Larrea C, Rodriguez RM. Crosstalk between hypoxia and ER stress response: a key regulator of macrophage polarization. Front Immunol. 2019;10:2951.

18. Wei C, Yang X, Liu N, Geng J, Tai Y, Sun Z, et al. Tumor microenvironment regulation by the endoplasmic reticulum stress transmission mediator golgi protein 73 in mice. Hepatology. 2019;70:851-70.

19. Dkhil MA, Al-Quraishy S, Moneim AEA. Ziziphus spina-christi leaf extract pretreatment inhibits liver and spleen injury in a mouse model of sepsis via antioxidant and anti-inflammatory effects. Inflammopharmacology. 2018;26:779-91.

20. Hoque R, Farooq A, Ghani A, Gorelick F, Mehal WZ. Lactate reduces liver and pancreatic injury in Toll-like receptor- and inflammasome-mediated inflammation via GPR81-mediated suppression of innate immunity. Gastroenterology. 2014;146:1763-74.

21. Tan $S$, Lu Y, Xu M, Huang $X$, Liu $H$, Jiang J, et al. beta-Arrestin1 enhances liver fibrosis through autophagy-mediated Snail signaling. FASEB J. 2019;33:2000-16.

22. Shi T, Song W. Xu R. Autophagy and ER stress in LPS/GalNinduced acute liver injury. Mol Med Rep. 2017;16:7001-5.

23. Axten JM, Medina JR, Feng Y, Shu A, Romeril SP, Grant SW, et al. Discovery of 7methyl-5-(1-\{[3-(trifluoromethyl)phenyl] 3 acetyl\}-2,3-dihydro-1H-indol-5-yl)-7H-pyrrolo[2,3-d]pyrimidin-4-amine (GSK2606414), a potent and selective first-in-class inhibitor of protein kinase $\mathrm{R}$ (PKR)-like endoplasmic reticulum kinase (PERK). J Med Chem. 2012;55:7193-207.

24. Han S, Li Z, Ji P, Jia Y, Bai X, Cai W, et al. MCPIP1 alleviated lipopolysaccharideinduced liver injury by regulating SIRT1 via modulation of microRNA-9. J Cell Physiol. 2019;234:22450-62.

25. Zeng Q, Shu J, Hu Q, Zhou SH, Qian YM, Hu MH, et al. Apoptosis in human myelodysplastic syndrome CD34+ cells is modulated by the upregulation of TLRs and histone $\mathrm{H} 4$ acetylation via a beta-arrestin 1 dependent mechanism. Exp Cell Res. 2016;340:22-31.

26. Porter KJ, Gonipeta B, Parvataneni S, Appledorn DM, Patial S, Sharma D, et al. Regulation of lipopolysaccharide-induced inflammatory response and endotoxemia by beta-arrestins. J Cell Physiol. 2010;225:406-16.

27. Tao $L$, Lin $X$, Tan $S$, Lei $Y$, Liu $H$, Guo $Y$, et al. beta-Arrestin1 alleviates acute pancreatitis via repression of NF-kappaBp65 activation. J Gastroenterol Hepatol. 2019;34:284-92.

28. Zhang Z, Xu X, Tian W, Jiang R, Lu Y, Sun Q, et al. ARRB1 inhibits non-alcoholic steatohepatitis progression by promoting GDF15 maturation. J Hepatol. 2020;72:976-89.

29. Liu J, Tang J, Zuo Y, Yu Y, Luo P, Yao X, et al. Stauntoside B inhibits macrophage activation by inhibiting NF-kappaB and ERK MAPK signalling. Pharm Res. 2016;111:303-15.

30. Lattin J, Zidar DA, Schroder K, Kellie S, Hume DA, Sweet MJ. G-protein-coupled receptor expression, function, and signaling in macrophages. J Leukoc Biol. 2007;82:16-32.

31. Yan T, Huang J, Nisar MF, Wan C, Huang W. The beneficial roles of SIRT1 in druginduced liver injury. Oxid Med Cell Longev. 2019;20198506195.

32. Tian X, Yan F, Zheng J, Cui X, Feng L, Li S, et al. Endoplasmic reticulum targeting ratiometric fluorescent probe for carboxylesterase 2 detection in drug-induced acute liver injury. Anal Chem. 2019;91:15840-5.

33. Petrasek J, Iracheta-Vellve A, Csak T, Satishchandran A, Kodys K, Kurt-Jones EA, et al. STING-IRF3 pathway links endoplasmic reticulum stress with hepatocyte apoptosis in early alcoholic liver disease. Proc Natl Acad Sci USA. 2013;110:16544-9.

\section{ACKNOWLEDGEMENTS}

We thank Professor Robert J Lefkowitz at Duke University for providing the ARRB1knockout mice.

\section{AUTHOR CONTRIBUTIONS}

$\mathrm{YL}$ designed and conducted trials and analyzed the data. SW made figures, tables, and wrote the manuscript. $\mathrm{HL}$ designed and conducted trials, analyzed the data and generated figures. $\mathrm{HZ}$ and $\mathrm{LC}$ helped with data collection, discussed the assumptions and participated in the manuscript preparation. YY helped with the data interpretation, participated in the data analysis and wrote the manuscript. BW supervised the project, designed the experiments, helped with the data interpretation, participated in the data analysis and wrote the manuscript.

\section{FUNDING}

This work was supported by grants from the Natural Science Foundation Team Project of Guangdong Province (2018B03031200), the National Natural Science Foundation of China (U1501224 and 81602122), and the Guangzhou Science and Technology Program (201604020118 and 201804010026).

\section{COMPETING INTERESTS}

The authors declare no competing interests.

\section{ETHICS APPROVAL AND CONSENT TO PARTICIPATE}

All animal experiments and relevant details were conducted in accordance with the approved guidelines and were approved by the committee on Animal Care and Use of Sun Yat-Sen University.

\section{CONSENT FOR PUBLICATION}

All authors agree with the content of the manuscript. 


\section{ADDITIONAL INFORMATION}

Supplementary information The online version contains supplementary material available at https://doi.org/10.1038/s41420-021-00615-9.

Correspondence and requests for materials should be addressed to Y.Y. or B.W.

Reprints and permission information is available at http://www.nature.com/ reprints

Publisher's note Springer Nature remains neutral with regard to jurisdictional claims in published maps and institutional affiliations.
Open Access This article is licensed under a Creative Commons Attribution 4.0 International License, which permits use, sharing, adaptation, distribution and reproduction in any medium or format, as long as you give appropriate credit to the original author(s) and the source, provide a link to the Creative Commons license, and indicate if changes were made. The images or other third party material in this article are included in the article's Creative Commons license, unless indicated otherwise in a credit line to the material. If material is not included in the article's Creative Commons license and your intended use is not permitted by statutory regulation or exceeds the permitted use, you will need to obtain permission directly from the copyright holder. To view a copy of this license, visit http://creativecommons.org/licenses/by/4.0/.

(c) The Author(s) 2021 